See discussions, stats, and author profiles for this publication at: https://www.researchgate.net/publication/328223035

\title{
Author accepted manuscript: Reduced Stroop Interference Under Stress: Decreased Cue Utilisation, Not Increased Executive Control
}

Article in Quarterly journal of experimental psychology (2006) · October 2018 Dol: $10.1177 / 1747021818809368$

\section{CITATIONS}

1 author:

Robert William Booth

Sabanci University

23 PUBLICATIONS 105 CITATIONS

SEE PROFILE
READS

23 
Reduced Stroop Interference Under Stress: Decreased Cue Utilisation, Not Increased Executive Control

Robert W. Booth

Sabanc1 University, Istanbul

Please cite as:

Booth, R.W. (2019). Reduced Stroop interference under stress: Decreased cue utilisation, not increased executive control. Quarterly Journal of Experimental Psychology, 72, 1522-1529. http://doi.org/10.1177/1747021818809368

Word count: 4283

\section{Author Note}

Robert W. Booth, Faculty of Arts and Social Sciences, Sabanc1 University, Turkey.

I am grateful to Zeynep Aydın for assistance with data collection. I have no conflict of interest regarding this work.

Please address correspondence to Robert W. Booth, Sabanc1 University, Faculty of Arts and Social Sciences, Orhanlı - Tuzla, 34956, İstanbul, Turkey. Tel: (+90) 216483 9242. Email: rob.booth.psych@gmail.com 


\begin{abstract}
Since the 1960s, researchers have been reporting that stress reduces Stroop interference. This is puzzling, as stress and anxiety typically have deleterious effects on cognitive control and performance. The traditional explanation is that stress reduces 'cue utilisation': it withdraws attentional resources from less-relevant stimuli (including the distracter word), meaning that the target colour is left with a stronger influence over response-selection. However, it could also be that stress somehow boosts distracter inhibition, or some other aspect of executive control. To test these two accounts, 59 students completed a Stroop task featuring occasional startlingly-loud sounds (high stress), or the same sounds at a lower, comfortable volume (low stress). Alongside standard Stroop interference, two measures of executive control--negative priming and conflict adaptation--were calculated from the Stroop data. Stress produced a clear reduction of Stroop interference, but it did not influence negative priming, and no conflict adaptation effects were detected at all. These findings support the cue utilisation account. Furthermore, for the first time stress was shown to reduce Stroop interference in a task with no congruent trials, showing that the effect does not result from stress's modulating any strategy changes participants might make in response to congruent trials.
\end{abstract}

Keywords: Stroop interference; stress; cue utilisation; executive control. 
Reduced Stroop Interference Under Stress: Decreased Cue Utilisation, Not Increased Executive Control

Since the 1960s, researchers have been reporting that stress reduces Stroop interference (e.g. Agnew \& Agnew, 1963; Houston, 1969; O'Malley \& Poplawsky, 1971; Tecce \& Happ, 1964). Stroop interference (Stroop, 1935) means that identifying the print colour of a word is impaired when that word is the name of a different colour: for example participants respond 'blue' more slowly to the incongruent colour word RED in blue print than they do to the non-colour word BED in blue print. More modern experiments with consistent presentation times and accurate response timing have tended to confirm that this interference is reduced under stressful, and especially under stressfully noisy, conditions (Booth \& Sharma, 2009; Chajut \& Algom, 2003; Hu, Bauer, Padmala, \& Pessoa, 2012; see also Hommel, Fischer, Colzato, van den Wildenberg, \& Cellini, 2012; Hoskin, Hunter, \& Woodruff, 2014; but see Brand, Schneider, \& Arntz, 1994; Kofman, Meiran, Greenberg, Balas, \& Cohen, 2006).

These results are a puzzle, given that modern theories generally focus on how stress and anxiety impair, rather than improve, attentional control (e.g. Eysenck, Derakshan, Santos, \& Calvo, 2007). Indeed, studies which examined self-report anxiety rather than externallyapplied stressors have found that anxiety increases interference (Basten, Stelzel, \& Fiebach, 2011; Booth \& Peker, 2017), possibly because anxiety can induce difficulties in goal maintenance (Spielberg et al., 2014). Attempts to explain stress's reduction of Stroop interference fall into two broad categories: cue utilisation accounts, and executive control accounts.

Cue utilisation theories (Callaway \& Dembo, 1958; Easterbrook, 1959; Kohn, 1954) assume that stress decreases one's ability to process the full range of information ('cues') 
present in the environment; it reduces the attentional resources available. In the Stroop task, the colour is the most important cue, and the word is less important. Under stress, attention is withdrawn from all less-important cues, including the distracter word; since less attention is allocated to the word, it interferes less with colour-identification. This is not assumed to be a strategic adjustment, but rather a side-effect of stress's impact on the limited-capacity (Broadbent, 1958) attention system, corresponding to the 'tunnel vision' often reported by individuals under stress (Baddeley, 1972; Staal, 2004). Published articles on stress and Stroop interference have tended to use some version of this idea to explain their findings (Booth \& Sharma, 2009; Chajut \& Algom, 2003; Hoskin et al., 2014; Hu et al., 2012).

The other way to account for stress's reduction of Stroop interference is to assume that stress somehow strengthens some aspects of executive control. Recent reviews of human and animal studies suggest that stressors, while generally impairing executive control, may enhance specific executive functions such as inhibition (Shields, Sazma, \& Yonelinas, 2016). These enhancements may be a direct result of the physiological stress response, or they may occur if stress causes participants to change their approach to the task (see Hockey, 1997): for example, participants may respond to stress by forgoing unnecessary task-irrelevant thinking during the experiment, and end up focusing more of their available cognitive resources on task performance (Klauer, Herfordt, \& Voss, 2008).

These two accounts can easily be tested. A standard Stroop task allows the calculation of two secondary measures of executive control: negative priming, and conflict adaptation. The predictions are simple: if stress's reduction of Stroop interference is a result of increasing executive control, then this decrease in Stroop interference should be accompanied by an increase in negative priming and/or conflict adaptation effects. If however stress reduces Stroop interference by reducing cue utilisation, then no increase in either effect should be observed. 


\section{Negative Priming}

Efficient Stroop performance requires efficient inhibition of the word, and of the tendency to respond to it (Miyake et al., 2000). Stress may strengthen distracter inhibition, although the literature on this is somewhat mixed (Shields et al., 2016). It therefore seems plausible that stress might decrease Stroop interference because it boosts inhibition. One way to estimate inhibition strength within a regular Stroop task is to measure negative priming. Originally discovered in the Stroop task (Neill, 1977) and since replicated in other paradigms, negative priming refers to a delayed response when the target colour on the current trial matches the distracter word on the previous trial (an 'ignored repetition' trial). The effect partly reflects interference from episodic memories of earlier trials but, importantly for this discussion, it also partly reflects residual inhibition of the deselected word from the previous trial (Tipper, 2001). Although interest in negative priming has waned, a recent review (Frings, Schneider, \& Fox, 2015) concluded that the effect was suitable for investigating individual differences in the ability to ignore distracters. Importantly, although negative priming partly reflects efficient executive control over distracter processing, it is actually a worsening of performance--an increased response time--on ignored repetition trials. If stress reduces Stroop interference by boosting executive deselection of the distracter words, then this overall improvement in performance under stress should be accompanied by increased response times on ignored repetition trials.

\section{Conflict Adaptation}

Conflict adaptation (also called the Gratton effect; Gratton, Coles, \& Donchin, 1992) refers to the fact that Stroop interference is typically smaller on trials following an incongruent trial that it is on trials following a control trial (Notebaert, Gevers, Verbruggen, \& Liefooghe, 2006). Different processes contribute to this effect, but it partly reflects executive modulation of attentional selectivity: when the system sees an incongruent trial 
featuring high conflict between word and colour, showing that reading the word is unhelpful for task performance, it responds by boosting selectivity. This boosted selectivity slowly decays when the system sees lower-conflict control trials. With appropriate data preparation (see Results), one can isolate this executive modulation component of the effect (Notebaert et al., 2006; see also Booth \& Peker, 2017). Schuch, Zweerings, Hirsch, and Koch (2017) have recently claimed that stress can exaggerate conflict adaptation; if true, this may explain stress's reduction of Stroop interference, because efficient conflict adaptation will decrease mean interference across the experiment if incongruent trials are fairly frequent, which they typically are. If indeed stress reduces Stroop interference by exaggerating such executive modulation of selectivity in response to conflict, then this reduction in interference should be accompanied by increased conflict adaptation effects, such that stress's reduction of Stroop interference should be greater on trials following incongruent trials.

\section{Congruent Trial Problem}

The possibility that stress modulates adaptive executive control raises a further issue. The experiments showing that stress reduces Stroop interference have all included congruent trials, in which the colour and word match (e.g. RED in red print; Chajut \& Algom, 2003; Hu et al., 2012; see also Hommel et al., 2012). This is a problem because including a substantial proportion of congruent trials in Stroop-like tasks increases interference, ostensibly because the ignore-the-word task demand is less strongly reinforced and word-reading becomes a more viable strategy for successful performance (Bugg \& Crump, 2012). If stress somehow reduces participants' strategic or executive adjustment in response to the congruent trials, this will manifest itself as an apparent reduction in Stroop interference. Indeed, Booth and Sharma's (2009; although see Gur \& Algom, 2016) results suggested that stress only reduced interference when congruent trials were present. It is therefore important to confirm whether stress still reduces interference in a Stroop task with no congruent trials. 


\section{The Present Study}

This experiment tested the effects of an acute stressor on performance in the Stroop task. The Stroop task contained only incongruent and non-linguistic control trials, to assess whether stress's reduction of Stroop interference depends on the presence of congruent trials. Assuming this reduction was found, negative priming and conflict adaptation would be examined: if stress's reduction of Stroop interference is due to an increase in executive control of attention, then stress should also affect these Stroop-derived dependent variables.

Often negative priming studies employ a non-random trial order, to ensure a high and consistent number of ignored-repetition trials. In this experiment, incongruent and control trials were presented in a random order, since the aim was to assess the ability of boosted inhibition to explain stress effects in the context of an ordinary Stroop task, and because there was some concern that stress might influence participants' ability to recognise and predict a non-random trial order, confounding the results.

\section{Method}

\section{Participants}

Fifty-nine undergraduates (11 males; $\left.M_{\mathrm{age}}=19.22, S D_{\mathrm{age}}=0.93\right)$ from $\mathrm{MEF}$ University, Istanbul, participated for course credit. All were native Turkish speakers with normal or corrected vision and hearing. Five more participants were tested, but scored less than $90 \%$ correct on the Stroop task; their data were excluded from all analyses. The study was approved by the Institutional Review Board.

\section{Design}

The experiment employed a 2 (trial type: incongruent or control, within participants) $\times 2$ (stress: high or low, between participants) mixed design. The dependent variables were response time and accuracy. 


\section{Apparatus and Stimuli}

The experiment was run using E-Prime 2.0.10 and a 24" LCD monitor. Responses were collected via a Chronos response box, which also controlled the sound stimuli. The outermost four keys of this box were marked red, blue, yellow and green, from left to right, via the integral LEDs.

The Stroop task included 120 incongruent trials and 120 control trials. Incongruent trials consisted of the Turkish words KIZIL (crimson), MAVİ (blue), SARI (yellow) and YEŞIL (green) presented 10 times in each mismatching colour. Control trials were identical except that the words were replaced by +++++ ,\#\#\#, XXXX and ?????. Stroop stimuli were presented onscreen in boldface Courier New, and subtended approximately $2.60^{\circ}$ by $0.65^{\circ}$. Participants were instructed to press the key corresponding to the font colour, as quickly and accurately as possible. There was a $500 \mathrm{~ms}$ interval between each response and the next trial. The Stroop task was preceded by a practice session, which was identical to the main task except that 12 animal names were presented twice each in each of the four colours.

\section{Procedure}

Participants were tested individually. After signing consent, they completed the practice trials, having been told to use this time to learn the response keys. Their baseline stress level was then assessed using an onscreen visual analogue scale: participants used a mouse to indicate where on a horizontal line, labelled with the Turkish for 'Not stressed at all' at the left and 'Extremely stressed' at the right, their current stress level fell. Their response was later converted into a percentage score.

Next, participants were told that, during the upcoming testing session, they would hear 'beep' sounds at random, unpredictable intervals. Presenting aversive stimuli at unpredictable times is a common experimental model of stress and anxiety (Robinson, Vytal, Cornwell, \& Grillon, 2013). The high stress group were told that these sounds were 'very 
loud', and the sounds were played at $96 \mathrm{dBA}$. The low stress group were told the sounds would be 'very quiet', and they were played at $60 \mathrm{dBA}$. To avoid adding noise to the data by unnecessarily varying different participants' experiences in the experiment, all participants actually heard sounds at the beginning of the Stroop task, after 80 trials, and after 160 trials. The sounds were one-second tones at $9 \mathrm{kHz}$, played over headphones. After completing the Stroop task, participants again rated their stress level on a second visual analogue scale.

\section{Results}

The raw data are available at https://dx.doi.org/10.17605/osf.io/w7y85.

\section{Manipulation Check}

Before the noise manipulation was introduced, the two groups did not differ in VASassessed stress level, $t(57)=1.03, p=.31$, see Table 1; by the end of the Stroop task, the high stress group reported significantly higher stress, $t(57)=2.33, p=.02$. Furthermore, the high stress group's stress increased between these two times, $t(28)=2.53, p=.02$, whereas the low stress group's stress level did not change, $t(29)=-.12, p=.90$. These results suggest the stress manipulation was successful.

\section{Overall Stroop Performance}

Correct response times were subjected to van Selst and Jolicoeur's (1994) nonrecursive outlier trimming procedure. This procedure varies the outlier-exclusion criterion for each condition within each subject based on the number of observations, reducing the risk of biasing smaller samples with overly-inclusive criteria. This is especially important for the present experiment, in which the number of observations varied substantially between dependent variables and between participants; separate outlier-trimmings were performed for the analyses of overall Stroop performance, negative priming, and conflict adaptation. Remaining response times were subjected to a 2 (stress group, high or low) $\times 2$ (trial type, incongruent or control) mixed ANOVA. There was a significant main effect of trial type, 
indicating the presence of Stroop interference, $F(1,57)=45.89, \eta_{p}{ }^{2}=.45, p<.001$, but no main effect of stress, $F(1,57)=0.06, \eta_{p}^{2}=.001, p=.81$. Importantly and as predicted, there was a significant interaction, $F(1,57)=11.56, \eta_{p}{ }^{2}=.17, p=.001$, indicating that Stroop interference was reduced in the high stress condition (see Table 1, Figure 1). Note that stress did not affect RT on control trials, $t(57)=0.48, p=.63$. To provide consistency with later analyses (see below), this analysis was repeated as a Bayesian ANOVA, using JASP (JASP Team, 2018). Since the interaction was the effect of interest, a model including both main effects and the interaction was compared to a null model including just the main effects. This allows one to calculate how much more likely the observed data are if the interaction is present, vs. if the interaction is absent $\left(\mathrm{BF}_{10}\right)$. The $\mathrm{BF}_{10}$ for the model including the interaction was 23.46, which represents strong evidence that stress and trial type interact, i.e. that stress moderates Stroop interference.

Accuracy rates were subjected to the same analysis. Neither main effect was significant, $F \mathrm{~s}<.51$, but the interaction was marginal, $F(1,57)=4.02, \eta_{p}{ }^{2}=.07, p=.05$, indicating again that interference tended to be reduced in high stress participants.

\section{Negative Priming}

Outlier trimming was redone from the beginning for ignored repetition and unprimed incongruent trials; $M=14.20$ (range: 8 -20) ignored repetition trials and $M=98.42$ (range: 90 106) unprimed trials were retained for each participant. They were then subjected to a 2 (stress group, high or low) $\times 2$ (trial type, ignored repetition or unprimed) mixed ANOVA. There was a significant main effect of trial type indicating the presence of negative priming, $F(1,57)=9.90, \eta_{p}^{2}=.15, p=.003$, but no main effect of stress group, $F(1,57)=0.43, \eta_{p}{ }^{2}=$ $.007, p=.52$, and no interaction, $F(1,57)=0.87, \eta_{p}{ }^{2}=.01, p=.36$, indicating that negative priming was not influenced by stress; see Table 1. A sensitivity analysis in G*Power indicated that the study had $80 \%$ power to detect an interaction as small as $\eta_{p}{ }^{2}=.011$, so 
while it remains possible that stress does truly influence negative priming, it seems quite unlikely that this influence is of comparable size to the relatively large effect of stress on Stroop interference $\left(\eta_{p}^{2}=.17\right)$.

Given the theoretical importance of this null result, a Bayesian mixed ANOVA was run on the same data. The Bayesian approach allows one to calculate how much more likely the observed data are if the tested effect is absent in the population, relative to if the tested effect is present in the population $\left(\mathrm{BF}_{01}\right.$; conceptually, the opposite of $\mathrm{BF}_{10}$, calculated above). Since the interaction was the effect of interest, a model including both main effects and the interaction was compared to a null model including just the main effects. The $\mathrm{BF}_{01}$ for the model including the interaction was 2.77 , indicating anecdotal evidence that there truly is no interaction between trial type and stress group, i.e. no effect of stress on negative priming.

\section{Conflict Adaptation}

Following Notebaert et al. (2006), only trials where both the word and colour changed from the previous trial were used for these analyses: this helps to isolate conflict adaptation from low-level repetition effects. Incongruent and control trials following incongruent and control trials were subjected to their own outlier trimming, and $M=156.05$ (range: 142-174) trials were retained for each participant. These data were then subjected to a 2 (stress group, high or low $) \times 2$ (trial type, incongruent or control) $\times 2$ (previous trial type, incongruent or control) mixed ANOVA. The main effect of trial type, $F(1,57)=38.05, \eta_{p}{ }^{2}=.40, p<.001$, and the interaction between trial type and stress group, $F(1,57)=8.30, \eta_{p}{ }^{2}=.13, p=.006$, were significant as before; however, there was no interaction between trial type and previous trial type, $F(1,57)=1.90, \eta_{p}^{2}=.03, p=.17$, and no three-way interaction, $F(1,57)=0.002$, $\eta_{p}{ }^{2}<.001, p=.96$, indicating that in these data there was no conflict adaptation effect, and 
that conflict adaptation did not differ with stress (see Table 1, Figure 1). No other effects were significant, all $F \mathrm{~s}<2.05$.

Again, a Bayesian mixed ANOVA was conducted on these data, to assess the level of evidence that the three-way interaction is truly absent in the population. The model including all effects was compared to a null model including all effects except the three-way interaction. The $\mathrm{BF}_{01}$ for the tested model was 3.81, representing reasonable evidence that there truly is no three-way interaction, i.e. that stress does not influence conflict adaptation.

\section{Discussion}

Replicating previous studies (e.g. Chajut \& Algom, 2003), this experiment showed a clear reduction in Stroop interference under stress. For the first time, this happened even though the Stroop task included no congruent trials; this removes the concern raised by Booth and Sharma (2009) that the effect might depend on the presence of congruent trials, which can influence the strategies employed by participants (Bugg \& Crump, 2012; Lindsay \& Jacoby, 1994). These results, together with the fact that stress did not influence negative priming or conflict adaptation, support cue utilisation accounts: they suggest that stress reduces Stroop interference because it withdraws attentional resources from less-relevant cues, including the word.

Despite the effect of stress on Stroop interference being so clear and of medium-tolarge size, there was no effect of stress on either negative priming or conflict adaptation. While negative priming partly reflects episodic memory processes, most theorists agree that it also partly reflects inhibition of the distracter word (Tipper, 2001), so the fact that stress did not affect this priming suggests increased inhibition or stronger deselection of the word cannot explain stress's effect on Stroop interference. Stress's effect on interference was so clear that it is hard to imagine that undetectably-small variations in deselecting distracters and conflict adaptation could account for it. Negative priming, while not approaching the size of 
the Stroop interference measured in this experiment $\left(\eta_{p}{ }^{2}=.45\right)$, was nevertheless a substantial effect $\left(\eta_{p}^{2}=.15\right)$, so the experiment seems to have been sensitive enough to negative priming that, if stress did affect negative priming, that effect would have been detected. Therefore, these results suggest that stress does not cause a strengthening or strategic re-deployment of executive control resources in Stroop experiments, but instead increases the efficiency of selective attention.

Note that it is not being argued that net Stroop interference, or the executive control exerted during performance of the Stroop task, are purely a function of negative priming and conflict adaptation: both Stroop interference and executive control of attention are much more complex than this. It is merely being argued that a modulation of executive control of attention in the Stroop task might tend to modulate negative priming and/or conflict adaptation too. Therefore, the fact that stress had a clear effect on Stroop interference but no effect on negative priming or conflict adaptation does not conclusively prove that stress does not modulate interference via executive control, but it does suggest that this is unlikely. I am grateful to an anonymous reviewer for pointing out that interference and conflict adaptation can be unrelated in certain circumstances (e.g. Kuhbandner \& Zehetleitner, 2011): this actually supports the contention that stress does not reduce Stroop interference by boosting conflict adaptation.

It is not clear why no conflict adaptation effects were found in this experiment: our laboratory has previously found such effects using very similar methodology (Booth \& Peker, 2017). This earlier study found a conflict adaptation effect of $d=.31$; the current experiment had a reasonable power of .76 to detect such an effect, and if it is true that stress boosts conflict adaptation, the predicted effect size for this experiment - where half the participants were under stress - would be larger than that found by Booth and Peker. Also, although conflict adaptation experiments typically employ congruent rather than control trials as their 
baseline, Booth and Peker found robust conflict adaptation effects in a Stroop task with only incongruent and control trials, just like those used in the present experiment. It is possible that the unpredictable sounds distracted participants to the extent that they did not focus on optimising their performance in the Stroop task. Whatever the reason, these null findings do not detract from the central message of this article: if no trace of conflict adaptation has been seen in this experiment, then variations in conflict adaptation are unlikely to account for the substantial effect of stress on Stroop interference in these data.

In contrast to the findings of Hu et al. (2012), control trial RT was not increased by stress. This does not disprove these authors' hypothesis that stress can cause both general slowing and reduced cue-utilisation, but it does demonstrate that general slowing is not necessary for the reduction in distracter interference to be observed. More generally, the lack of a stress effect on control RT together with the lack of a stress main effect on RT or accuracy suggests that stress's effect on interference is not the result of an overall change in processing time or motivation to perform well (McFall, Jamieson, \& Harkins, 2009).

Gur and Algom (2016) also examined why Stroop interference decreases in stress, and drew the opposite conclusion to that promoted here. They found that, although stress reduced Stroop interference in their sample, it did not modulate the proportion-congruent effect: the tendency for Stroop interference to increase when proportionately more congruent trials are included in the task. Gur and Algom therefore concluded that their participants could not be attending less to the words when stressed, and so rejected the cue-utilisation account. Their experiment is very similar to a larger study from our laboratory (Booth \& Sharma, 2009), which found that stress did reduce the proportion-congruent effect, but only in participants with high working memory capacity. The reason for these conflicting results is not clear, but one difference between these studies is that Gur and Algom measured the Stroop effect as the difference in response time between congruent and incongruent trials (no 
other trial types were presented), whereas Booth and Sharma and the current experiment measured Stroop interference as the difference between incongruent and nonlexical control trials. Gur and Algom's measure collapses Stroop interference (the performance impairment caused by the conflicting colour and word) and Stroop facilitation (the potential performance enhancement caused by the matching colour and word) together. The nature and causes of Stroop facilitation are still debated (e.g Brown, 2011), but facilitation and interference do respond differently to various manipulations (e.g. Carter, Robertson, \& Nordahl, 1992; MacLeod, 1998). The proportion congruent effect may partially occur because large numbers of congruent trials lead the participant to pay more attention to the word, or even to respond to the word on some trials (on a congruent trial, responding to the word yields the correct response; Bugg \& Crump, 2012; Kane \& Engle, 2003); so proportion congruent is likely to have different effects on interference and facilitation (Lindsay \& Jacoby, 1994). Until stress's influence on the proportion congruent effect in both interference and facilitation is directly studied, the reasons for the apparent inconsistency among these three studies will remain unclear.

These results, together with related literature tracing back to the 1960s, highlight an important dissociation between manipulated stressors, which can improve some aspects of executive control and attentional selection, and self-reported anxiety, which has a more uniformly negative influence on executive control in general and Stroop interference in particular (see Robinson et al., 2013). In their review, Robinson et al. were unable to suggest a convincing reason for this discrepancy: it may reflect the differences (LeDoux, 2014) between emotion as a subjective experience of the participant (corresponding to anxiety, in this case) and emotion as an elicited response to external stimuli (corresponding to stress, resulting from some manipulation such as unpredictable startling noises). Since modern theories of anxiety tend to base themselves on threat conditioning literature (see Robinson et 
al., 2013), it is important to resolve these differences in definition, and try to understand cognitive results of self-report anxiety versus applied stressors.

One potential limitation of this experiment concerns the stress manipulation: this may have been relatively mild (cf. Chajut \& Algom, 2003). It is possible that a stronger manipulation may have a significant effect on negative priming or conflict adaptation, although again, the fact that the current manipulation so clearly affected Stroop interference suggests it may not. Future replications with different stress manipulations, and which verify participants' stress levels physiologically, would be valuable.

These findings highlight the fact that, even though stress apparently restricts the attentional resources which participants may allocate to different stimuli, this does not necessarily manifest itself as a deterioration in performance; here, stress has reduced attentional resources, improving participants' performance on a classic executive control task. Future research must work to specify exactly how stress and negative affect generally influence executive control, so as to more accurately predict how these variables might affect performance in specific situations. 


\section{References}

Agnew, N., \& Agnew, M. (1963). Drive level effects on tasks of narrow and broad attention. Quarterly Journal of Experimental Psychology, 15, 58-62. doi:10.1080/17470216308416552

Baddeley, A.D. (1972). Selective attention and performance in dangerous environments. British Journal of Psychology, 63, 537-546. doi:10.1111/j.2044-8295.1972.tb01304.x

Basten, U., Stelzel, C., \& Fiebach, C.J. (2011). Trait anxiety modulates the neural efficiency of inhibitory control. Journal of Cognitive Neuroscience, 23, 3132-3145. doi: 10.1162/jocn_a_00003

Booth, R.W., \& Peker, M. (2017). State anxiety impairs attentional control when other sources of control are minimal. Cognition and Emotion, 31, 1004-1011. doi: $10.1080 / 02699931.2016 .1172474$

Booth, R.W., \& Sharma, D. (2009). Stress reduces attention to irrelevant information: Evidence from the Stroop task. Motivation and Emotion, 33, 412-418. doi:10.1007/s11031-009-9141-5

Brand, N., Schneider, N., \& Arntz, P. (1994). Information processing efficiency and noise: interactions with personal rigidity. Personality and Individual Differences, 18, 571579. doi:10.1016/0191-8869(94)00203-5

Broadbent, D.E. (1958). Perception and communication. London: Pergamon Press.

Brown, T.L. (2011). The relationship between Stroop interference and facilitation effects: Statistical artifacts, baselines, and a reassessment. Journal of Experimental Psychology: Human Perception and Performance, 37, 85-99. doi:10.1037/a0019252

Bugg, J.M., \& Crump, M.J.C. (2012). In support of a distinction between voluntary and stimulus-driven control: A review of the literature on proportion congruent effects. Frontiers in Psychology, 3, 367. doi: 10.3389/fpsyg.2012.00367 
Callaway, E., \& Dembo, D. (1958). Narrowed attention: a psychological phenomenon that accompanies a certain physiological change. A. M. A. Archives of Neurology and Psychiatry, 79, 74-90. doi:10.1001/archneurpsyc.1958.02340010092008

Carter, C.S., Robertson, L.C., \& Nordahl, T.E. (1992). Abnormal processing of irrelevant information in chronic schizophrenia: Selective enhancement of Stroop facilitation. Psychiatry Research, 41, 137-146. doi:10.1016/0165-1781(92)90105-C

Chajut, E., \& Algom, D. (2003). Selective attention improves under stress: Implications for theories of social cognition. Journal of Personality and Social Psychology, 85, 231248. doi:10.1037/0022-3514.85.2.231

Easterbrook, J.A. (1959). The effect of emotion on cue utilization and the organization of behavior. Psychological Review, 66, 183-201. doi:10.1037/h0047707

Eysenck, M.W., Derakshan, N., Santos, R., \& Calvo, M.G. (2007). Anxiety and cognitive performance: Attentional control theory. Emotion, 7, 336-353. doi:10.1037/15283542.7.2.336

Frings, C., Schneider, K.K., \& Fox, E. (2015). The negative priming paradigm: An update and implications for selective attention. Psychonomic Bulletin \& Review, 22, 1577 1597. doi:10.3758/s13423-015-0841-4

Gratton, G., Coles, M.G.H., \& Donchin, E. (1992). Optimizing the use of information: Strategic control of activation of responses. Journal of Experimental Psychology: General, 121, 480-506. doi: 10.1037/0096-3445.121.4.480

Gur, T., \& Algom, D. (2016). Selective attention under stress: Evidence from the Stroop effect. In K. A. Moore, P. Buchwald, F. N.-A. Alhija \& M. Israelasvili (Eds.), Stress and anxiety: Strategies, opportunities, and adaptation (pp. 71-78). Berlin: Logos. 
Hockey, G.R.J. (1997). Compensatory control in the regulation of human performance under stress and high workload: A cognitive-energetical framework. Biological Psychology, 45, 73-93. doi:10.1016/S0301-0511(96)05223-4

Hommel, B., Fischer, R., Colzato, L.S., van den Wildenberg, W.P.M., \& Cellini, C. (2012). The effect of fMRI (noise) on cognitive control. Journal of Experimental Psychology: Human Perception and Performance, 38, 290-301. doi: 10.1037/a0026353

Hoskin, R., Hunter, M.D., \& Woodruff, P.W.R. (2014). Stress improves selective attention towards emotionally neutral left ear stimuli. Acta Psychologica, 151, 214-221. doi: 10.1016/j.actpsy.2014.06.010

Houston, B.K. (1969). Noise, task difficulty, and Stroop color-word performance. Journal of Experimental Psychology, 83, 403-404. doi:10.1037/h0028118

Hu, K., Bauer, A., Padmala, S., \& Pessoa, L. (2012). Threat of bodily harm has opposing effects on cognition. Emotion, 12, 28-32. doi: 10.1037/a0024345

JASP Team. (2018). JASP (Version 0.8.5.1) [Computer software].

Kane, M.J., \& Engle, R.W. (2003). Working-memory capacity and the control of attention: The contributions of goal neglect, response competition, and task set to Stroop interference. Journal of Experimental Psychology: General, 132, 47-70. doi: $10.1037 / 0096-3445.132 .1 .47$

Klauer, K.C., Herfordt, J., \& Voss, A. (2008). Social presence effects on the Stroop task: Boundary conditions and an alternative account. Journal of Experimental Social Psychology, 44, 469-476. doi:10.1016/j.jesp.2007.02.009

Kofman, O., Meiran, N., Greenberg, E., Balas, M., \& Cohen, H. (2006). Enhanced performance on executive functions associated with examination stress: Evidence from task-switching and Stroop paradigms. Cognition and Emotion, 20, 577-595. doi: $10.1080 / 02699930500270913$ 
Kohn, H. (1954). The effect of variations of intensity of experimentally induced stress situations upon certain aspects of perception and performance. Journal of Genetic Psychology, 85, 289-304. doi:10.1080/00221325.1954.10532884

Kuhbandner, C., \& Zehetleitner, M. (2011). Dissociable effects of valence and arousal in adaptive executive control. PLOS ONE, 6, 29287. doi:10.1371/journal.pone.0029287

LeDoux, J.E. (2014). Coming to terms with fear. Proceedings of the National Academy of Sciences, 111, 2871-2878. doi: 10.1073/pnas.1400335111

Lindsay, D.S., \& Jacoby, L.L. (1994). Stroop process dissociations: The relationship between facilitation and interference. Journal of Experimental Psychology: Human Perception and Performance, 20, 219-234. doi:10.1037/0096-1523.20.2.219

MacLeod, C.M. (1998). Training on integrated versus separated Stroop tasks: The progression of interference and facilitation. Memory \& Cognition, 26, 201-211. doi:10.3758/BF03201133

McFall, S.R., Jamieson, J.P., \& Harkins, S.G. (2009). Testing the mere effort account of the evaluation-performance relationship. Journal of Personality and Social Psychology, 96, 135-154. doi:10.1037/a0012878

Miyake, A., Friedman, N.P., Emerson, M.J., Witzki, A.H., Howerter, A., \& Wager, T.D. (2000). The unity and diversity of executive functions and their contributions to complex “frontal lobe”' tasks: A latent variable analysis. Cognitive Psychology, 41, 49-100. doi:10.1006/cogp.1999.0734

Neill, W.T. (1977). Inhibitory and facilitatory processes in selective attention. Journal of Experimental Psychology: Human Perception and Performance, 3, 444-450. doi:10.1037/0096-1523.3.3.444 
Notebaert, W., Gevers, W., Verbruggen, F., \& Liefooghe, B. (2006). Top-down and bottomup sequential modulations of congruency effects. Psychonomic Bulletin and Review, 13, 112-117. doi:10.3758/BF03193821

O'Malley, J.J., \& Poplawsky, A. (1971). Noise-induced arousal and breadth of attention. Perceptual and Motor Skills, 33, 887-890. doi:10.2466/pms.1971.33.3.887

Robinson, O.J., Vytal, K., Cornwell, B.R., \& Grillon, C. (2013). The impact of anxiety upon cognition: Perspectives from human threat of shock studies. Frontiers in Human Neuroscience, 7, 203. doi: 10.3389/fnhum.2013.00203

Schuch, S., Zweerings, J., Hirsch, P., \& Kock, I. (2017). Conflict adaptation in positive and negative mood: Applying a success-failure manipulation. Acta Psychologica, 176, 1122. doi: 10.1016/j.actpsy.2017.03.005

Shields, G.S., Sazma, M.A., \& Yonelinas, A.P. (2016). The effects of acute stress on core executive functions: A meta-analysis and comparison with cortisol. Neuroscience and Biobehavioral Reviews, 68, 651-668. doi: 10.1016/j.neubiorev.2016.06.038

Spielberg, J.M., Miller, G.A., Warren, S.L., Sutton, B.P., Banich, M.T., \& Heller, W. (2014). Transdiagnostic dimensions of anxiety and depression moderate motivation-related brain networks during goal maintenance. Depression and Anxiety, 31, 805-813. doi: $10.1002 /$ da. 22271

Staal, M.A. (2004). Stress, cognition, and human performance: a literature review and conceptual framework. Hanover, MD: National Aeronautics and Space Administration.

Stroop, J. (1935). Studies of interference in serial verbal reactions. Journal of Experimental Psychology, 18, 653-662. doi:10.1037/h0054651 
Tecce, J.J., \& Happ, S.J. (1964). Effects of shock-arousal on a card-sorting test of color-word interference. Perceptual and Motor Skills, 19, 905-906. doi:10.2466/pms.1964.19.3.905

Tipper, S.P. (2001). Does negative priming reflect inhibitory mechanisms? A review and integration of conflicting views. Quarterly Journal of Experimental Psychology, 54A, 321-343. doi:10.1080/713755969

van Selst, M., \& Jolicoeur, P. (1994). A solution to the effect of sample size on outlier elimination. Quarterly Journal of Experimental Psychology, 47A, 631-650. doi: 10.1080/14640749408401131 
Table 1

Means and standard deviations for the dependent variables under low and high stress.

\begin{tabular}{|c|c|c|c|c|c|}
\hline \multirow[t]{2}{*}{ Dependent Measure } & & \multicolumn{2}{|c|}{ Low Stress $(N=30)$} & \multicolumn{2}{|c|}{ High Stress $(N=29)$} \\
\hline & & $M$ & $S D$ & $M$ & $S D$ \\
\hline \multirow[t]{2}{*}{ VAS stress measure } & Before Practice & 23.60 & 24.99 & 30.34 & 25.12 \\
\hline & After Stroop task & 23.13 & 21.89 & 38.21 & 27.63 \\
\hline \multirow[t]{2}{*}{ Overall Stroop response time } & Incongruent trials & 764.80 & 163.10 & 735.60 & 91.34 \\
\hline & Control trials & 699.82 & 125.10 & 714.05 & 101.68 \\
\hline \multirow[t]{2}{*}{ Overall Stroop accuracy rate } & Incongruent trials & .964 & .032 & .974 & .022 \\
\hline & Control trials & .971 & .024 & .970 & .023 \\
\hline \multirow[t]{3}{*}{ Negative priming } & Ignored-repetition & 784.27 & 161.01 & 771.31 & 129.20 \\
\hline & incongruent trials & & & & \\
\hline & $\begin{array}{l}\text { Unprimed incongruent } \\
\text { trials }\end{array}$ & 761.09 & 163.74 & 728.66 & 87.57 \\
\hline \multirow[t]{4}{*}{ Conflict adaptation } & $\begin{array}{l}\text { Incongruent following } \\
\text { incongruent }\end{array}$ & 795.97 & 173.68 & 780.75 & 109.13 \\
\hline & $\begin{array}{l}\text { Control following } \\
\text { incongruent }\end{array}$ & 742.83 & 139.35 & 764.11 & 116.09 \\
\hline & $\begin{array}{l}\text { Incongruent following } \\
\text { control }\end{array}$ & 798.90 & 159.71 & 773.79 & 97.34 \\
\hline & $\begin{array}{l}\text { Control following } \\
\text { control }\end{array}$ & 736.46 & 122.99 & 748.44 & 108.84 \\
\hline
\end{tabular}




\section{Figure Captions}

Figure 1

Mean correct response times. Panel A shows the overall Stroop performance; Panel B shows negative priming; Panel C shows conflict adaptation, the difference between Stroop interference on trials following a control trial, and Stroop interference on trials following an incongruent trial. Error bars show $95 \%$ confidence intervals. 

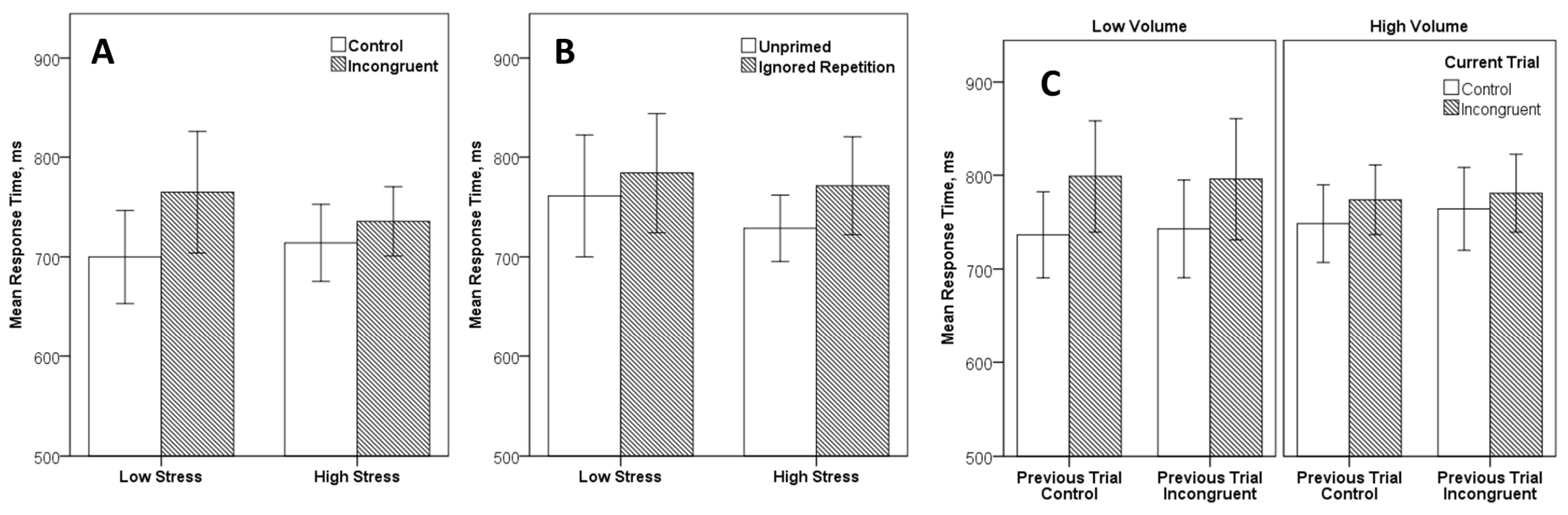